\title{
CONCEITOS E DESENHO NO PLANEJAMENTO DA PAISAGEM
}

MARIA DA GLORIA LANCI DA SILVA

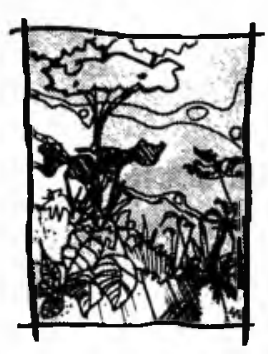

O presente trabalho parte dos conceitos de Paisagem e Ambiente para uma breve análise do planejamento da paisagem: os níveis de atuação do arquiteto paisagista e um método possível de abordagem do problema, confrontando com alguns padrões de desenho. Como ilustração das idéias expostas introduzimos uma discussão sobre o planejamento da paisagem litorânea.

Os conceitos adotados neste texto estão ainda em processo de construção por parte da autora e é parte da exploração em busca de uma metodologia de trabalho para a intervenção do arquiteto.

\section{CONCEITOS}

"Paisagem" e "Meio Ambiente" são conceitos que se inserem em universos disciplinares bastante amplos. Podemos nos referir à paisagem como uma imagem pictórica (um quadro à óleo, um cartão postal), por exemplo, ou ao meio ambiente como "natureza" simplesmente. Para o planejador da paisagem essas conceituações são obviamente estranhas, porém ainda este profissional se depara com idéias confusas, que não conseguem esclarecer questões básicas: a paisagem é tudo o que se observa ou também é uma imagem e não apenas a realidade visível? O meio ambiente deve ser compreendido no âmbito da escala humana ou pode ser extrapolado para a compreensão de todo o universo físico e biológico?

Para nós, meio ambiente é todo o universo físico e biológico que é percebido pelo homem, "envolvendo-o" e interagindo com ele. Neste universo que ora estabelecemos, o ser humano sempre determina o parâmetro da sua relação com o meio. A paisagem, por sua vez, é a estrutura morfológica do meio ambiente que deste é destacada pelo homem ao assumir um significado cultural, constituída de formas físicas expressivas com as quais ele interage conscientemente e não apenas biologicamente. Trata-se, portanto, de um conceito subjetivo, que pode ser compreendido na simples experiência da observação: através da visão, o observador seleciona um fragmento do espaço, que a partir daí adquire um caráter 
distinto. tornando-o um referencial nāo só físico como também cultural (ao nomeá-lo, relacioná-lo com atividades humanas ou com sua história passada). Esse "quadro mental" que se forma com a observaçāo do espaço tem conotações diferentes e varia com o decorrer do tempo. A paisagem é, portanto, o produto de um processo em constante transformação.

\section{PLANEJAMENTO DA PAISAGEM O PAPEL DO PLANEJADOR E SEUS NÍVEIS DE ATUAÇĀO}

O planejador deve abordar a paisagem como objeto de valoração pela sociedade, hierarquizado de acordo com a sua utilidade enquanto espaço, seja objetivo e real ou subjetivo e simbólico. Em qualquer escala de abordagem o planejamento será orientado em função do seu caráter público ou privado, de sua utilidade econômica ou estética, de sua abrangência local ou regional, de seus aspectos urbanos ou rurais, de um contexto cultural específico, etc.

Portanto, entre a sociedade e o suporte ecológico intervirá uma relação de custobenefício, podendo ser de caráter cultural, social ou econômico. O planejamento da paisagem tem como pressuposto avaliar as dinâmicas do meio ambiente e da sociedade para a compatibilização dessa relaçāo, indicando potenciais e impactos no processo de apropriação territorial.

O primeiro aporte metodológico é definir os objetivos do plano: por que é proposto, para quem e, numa pré-avaliaçāo, quais seriam os benefícios e impactos mais sensíveis. Este questionamento será orientado por uma postura que deve estabelecer uma estratégia de atuação, adotando critérios que perpassem todos os níveis do plano de uso e ocupação preestabelecidos.

O nível de atuação depende da abrangência ambiental, estética e funcional a ser exigida pela proposta. A relação conceito/escala de projeto estabelece-se paralelamente uma escala de prioridades. vinculada diretamente à abordagem e os objetivos predefinidos. Portanto, respostas adequadas serão obtidas com perguntas pertinentes ao objeto e à escala.

\section{PLANEJAMENTO DA PAISAGEM UM MÉTODO DE AVALIAÇĀO}

$\mathrm{Na}$ definição do escopo de cada nova proposta a ênfase a certos aspectos estruturais do lugar de estudo (físicos, biológicos, sociais, etc.) e a necessidade de determinadas fontes de informação (por exemplo dados de clima, vegetação, economia, etc.) acaba por circunstanciar todo o processo de análise e diagnóstico. No planejamento paisagístico as questões desenvolvem-se em três níveis bási- 
cos: a nível do ambiente físico e biológico para conhecimento do embasamento, a nível da sociedade e suas feições históricas e culturais para conhecimento do perfil do usuário, a nível do projeto para o conhecimento de sua viabilidade técnica e econômica.

Propomos três etapas básicas do processo de planejamento:

\section{Levantamento de dados}

Utilizando subsídios de diversas disciplinas, esta etapa é caracterizada pela coleta de informações dos aspectos abióticos (geologia, pedologia, clima, etc.), aspectos do meio biótico (fauna e flora) e aspectos sócioeconômicos da população envolvida (demografia, economia, cultura, saúde, educação, etc.).

\section{Análise dos dados lèvantados}

A paisagem e o meio ambiente onde ela se insere constituem um sistema de relações. Ao analisar dados obtidos no levantamento de qualquer área de projeto. devemos considerar o sistema no qual se situam. Não se pode estudar cursos d'água sem nos referirmos à bacia hidrográfica a qual pertencem, ou avaliar atividades econômicas sem introduzi-las no contexto social, mesmo extrapolando a área de estudo.

Esta etapa permite configurar o lugar estudado: a apropriação da sociedade pelo uso e ocupação do suporte, a estrutura morfológica, assim como o arcabouço legislativo, que nada mais é que um reflexo das atribuições que a sociedade dá a determinados lugares, com seus ecossistemas e paisagens. $O$ sistema paisagemmeio ambiente só pode ser composto através do entendimento dessas interações entre a sociedade e o suporte ecológico, pois as intervenções observadas tanto a nível das alterações na morfologia do território, como a nível das apropriações culturais que a sociedade lhe confere, são produtos da permanente inter-relação entre Homem e Meio.

\section{Diagnóstico e Plano}

O diagnóstico avaliará o suporte físico e social da área em si e também da área de influência do futuro projeto ou plano. A fase de projeto define o desenho e proposta técnica para realização dos objetivos preestabelecidos. $O$ trabalho final é decorrência do processo analítico e sua compatibilização com as metas a serem alcançadas: a capacidade do suporte físico e social e os impactos de possíveis projetos são produtos das linhas de atuação definidas no plano. 
Ao planejamento compete também definir as estratégias para a tomada de decisões que sofrem ingerências políticas. Estudos posteriores serão necessários para a elaboração de projetos de ocupação, mais próximos da escala do desenho urbano. Devem ser observados os vários níveis de execução da proposta e coordenados de acordo com um cronograma que considere as açōes da sociedade, do governo e dos setores empresariais e organizações civis envolvidos.

No escopo do trabalho, portanto, devem constar os conceitos que orientam sua metodologia, a justificação dos critérios utilizados e os parâmetros para execução de projetos, dados pela avaliação de suscetibilidade, estabilidade e potencialidade do território.

\section{PADRŌES DE DESENHO - AS ÁREAS DE TRANSIÇĀO}

Ao se tratar de planejamento da paisagem estamos nos referindo a possibilidades de transformação de um espaço, pois as atividades humanas dependem, numa primeira instância, do suporte físico sobre o qual produz e trabalha. A criação do espaço para o ser humano implica em processos de urbanização.

Na sociedade do final do séc. XX surge o dilema entre preservação $\mathrm{x}$ ocupação, quando a partir desse período, os processos de urbanização entram em confronto direto com o meio ambiente natural. A clássica diferenciação entre "cidade" e "campo" "livre" e "ocupado" "construído" e "não construído" ilustra bem esse quadro. Atualmente, o planejamento não mais se restringe a essa dicotomia e sim aproxima-se de uma configuração e de um desenho mais dialéticos. onde admite-se uma interpenetração de cheios e vazios e ao mesmo tempo intercalados por outras configurações, em constante associação com a dinâmica do ambiente preexistente. Não se resume apenas em definir-se o limite onde termina um padrão e começa outro, mas em compor-se um mosaico de padrões, intercambiáveis e concomitantemente distintos entre si.

Ao trabalharmos com a paisagem, em qualquer escala, seja lote, quadra, cidade ou região, nos deparamos sempre com a questão dos limites entre áreas livres e ocupadas, ou seja, os espaços de transição.

Os graus de ocupação dependem do referencial espacial. Na escala do lote, por exemplo, o referencial é o edifício: seu contorno delimita a área ocupada e o que "sobra", o que está fora deste limite. é a área livre, não construída. No contexto da cidade este aspecto da construção isolada se dilui: praças e outras áreas públicas afins determinam os espaços livres, pois são significativos enquanto áreas 
dentro do espaço urbano edificado. O jardim do lote não é mais relevante ao lado de centenas de outros, mas sim as áreas livres que ocupam o lugar de centenas de lotes.

Esta relativização livre/ocupado desenha no território um "mosaico" de padrões espaciais, que são mais ou menos significativos conforme a escala e o referencial, cujos intervalos são definidos pelos espaços de transição, permitindo uma maior "fluidez" e permeabilidade do desenho. Pode-se discutir a possibilidade de termos, lado a lado, áreas densamente ocupadas e áreas totalmente preservadas. Mas entendemos que esse é um desenho que nega uma visão sistêmica do processo, nega a postura que desde o início queremos demonstrar, considerando a paisagem fruto da relação homem/meio e que como tal não constitui um sistema fechado e estático. Ao invés disso podemos trabalhar com gradientes de ocupação variando em densidade, configuração e uso, procurando um desenho mais característico, não impondo modelos prontos. Conceitos como "área verde" "espaço livre", "parque", "espaço livre urbano" "área de preservação" "meio natural", "área de transição". etc., muitas vezes são utilizados para justificar padrões "viciados" de planejamento, com modelos preestabelecidos, que chegam a negar seus preceitos básicos.

\section{A NECESSIDADE DE UM PLANEJAMENTO DA PAISAGEM - O CASO DO LITORAL}

No processo de urbanização as dificuldades surgem para as propostas de ocupação em ambientes mais frágeis, em que os ecossistemas são mais abaláveis pela ocupação humana e a demanda de infra-estrutura compromete a qualidade desses ambientes, podendo causar vários tipos de impactos, desde mudanças no comportamento da fauna até alterações físicas drásticas.

No litoral é notadamente percebida a fragilização ambiental suscitada pela demanda de áreas de lazer: aparentemente. torna-se incompatível conciliar a vocação turística com a manutenção e conservação das características ecológicas originais do sítio. Ao lado de áreas totalmente antropizadas estão outras que conservam, fisica e simbolicamente, o cenário de "paraíso" "santuário ecológico" e outras definições que tão bem amoldam-se ao imaginário da praia e do mar. Na cultura ocidental, este cenário é o representante de uma qualidade de vida saudável, onde o homem pode ter um contato muito mais próximo com os elementos naturais: a areia, a água, o vento, o sol. A sensação da permanência à beira-mar é de liberdade e desprendimento.

Mas em direção ao interior da faixa litorânea, na região de restinga, lugar da vida urbana "civilizada" observamos um padrão que é refletido na ocupação 
deste território (tão privilegiado e cobiçado) que pouco corresponde àquelas experiências obtidas na praia. $\mathrm{O}$ apelo da vegetação e fauna "exuberantes" que os empreendedores de loteamentos de veraneio apresentam em seus informes de venda cai por terra ao nos depararmos com ocupaçōes que não só destróem por completo os ecossistemas como se afastam deles. O pano de fundo verde e viçoso se limita aos morros. deve ser intocável e não participa do desenho da trama urbana. A vegetação nativa é segregada nas "áreas de preservação" sempre "fora" dos limites da cidade.



Foto 1 - Vista aérea de loteamentos de praia em Ubatuba, onde as matas de restinga e atlântica estão confinadas a poucos segmentos

(Foto: Silvio S. Macedo)

Foto 2 - Praia em Alcobaça (Bahia) com a urbanização: somente a faixa de areia se mantém morfologicamente intacta

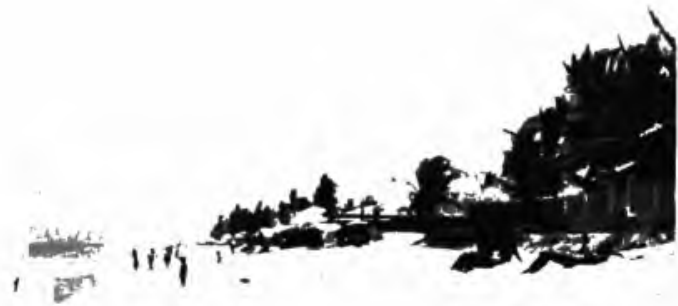
(Foto: Silvio S. Macedo)

As propostas de intervenção numa região litorânea justificam-se para atender esse desejo do homem de permanecer e mesmo habitar próximo às praias, mas não se pode esquecer do enorme potencial econômico do mar. principalmente como fonte de alimentação. As maiores cidades brasileiras, com exceção de São Paulo e Belo Horizonte, localizam-se no litoral: Porto Alegre, Rio de Janeiro, Salvador, Recife. Todas apresentam elevados níveis de poluição na faixa costeira, seja por atividade portuária, seja pela grande quantidade de dejetos que uma metrópole produz. Santos, o porto da maior metrópole brasileira, além desses problemas, por exemplo, é município vizinho de Cubatão. que se celebrizou por 
concentrar um dos mais altos teores de poluição atmosférica do mundo, hoje reduzido depois de medidas emergenciais de controle de emissão de poluentes. Nossa pergunta é: quais seriam os limites de ocupação dessas áreas e quais as alternativas de desenho que dispomos para manutenção da sucessão de ecossistemas (mar, praia, mangue, restinga, mata) ao mesmo tempo que se desenvolve e se incrementa as atividades econômicas?

Sendo uma área de grande apelo turístico é importante garantir acessos para desfrute da paisagem, seja da praia ou da serra. O planejador da paisagem deve oferecer opções de apropriação do espaço, explorando todas as possibilidades de uso e ocupação e estabelecer uma estratégia de conservação do meio natural, criando outras formas de interação com a sociedade, através de programas de educação ambiental, sem os quais não pode haver uma mudança de postura, levando o turista e o habitante do município a ter uma relação de cidadania com o lugar. conhecendo suas estruturas e usufruindo mais e melhor dos recursos naturais. A relação custo-benefício deve ser mensurada considerando não só as questōes no tempo presente, mas projetando-as no futuro, permitindo um grau de continuidade físico-temporal. Quanto ao desenho, este deve estabelecer gradientes de ocupação e de preservação variáveis em área, densidade, configuração, características ambientais e de uso, considerando itens como:

- Acessibilidade.

- Uso múltiplo de áreas.

- Manutenção da sucessão de ecossistemas.

- Manutenção da drenagem natural.

- Uso de diversos gradientes de ocupação.

- Maior restrição para áreas frágeis ainda não degradadas.

- Concentração de infra-estrutura e ocupação.

Áreas livres de uso público.

No caso do litoral paulista, podemos exemplificar (de uma forma bem genérica, pois sua conformação é bastante variada ao longo da costa, apresentando sensíveis diferenças entre o litoral norte e sul) algumas restrições e potencialidades de uso para os diversos ecossistemas:

Mata: A remoção da vegetação pode causar, com a exposição do solo, graves problemas de erosões. É uma região em constante movimento geológico, sofrendo processo natural de desabamento de encostas. 
Restinga: Dificuldades em relação à drenagem. Por outro lado, tem lençol freático mais profundo ao longo da costa do que próximo à serra (devido ao processo de formação dessa planície), apresentando também temperaturas mais amenas. por ser mais ventilado. É a área mais propícia ao assentamento urbano.

Mangue: Totalmente inadequado à edificação. Solo argiloso não oferece sustentação e é constantemente alagado. Muito importante na composição do sistema por ser depósito de matéria orgânica e "berçário" de muitas espécies marinhas. Sua destruição ou contaminação acarreta impactos não só locais como também em grande extensão do mar, atingindo a atividade pesqueira.

Praia: Lugar de maior atração para as pessoas. Não oferece condições físicas adequadas para assentamento. Remoção de dunas e vegetação desprotege a costa e altera a restinga e o mangue.

Poucos dados. como os apresentados, são suficientes para uma prévia compartimentação da paisagem. Cada compartimento tem características próprias que desenharão diferentes esquemas de graus de conservação $x$ graus de ocupação. Por sua vez o conjunto destes esquemas traça o perfil de uso do lugar. Este método de inferências progressivas, pois cada variável e cada dado podem combinar de muitas maneiras para a formação do quadro total, permite muitos desenhos. A opção de escolha será dada pela postura conceitual do plano: isto é inevitável. Haverá sempre op̧̧ões para atender uma intenção que privilegie os aspectos mais sociais. ou mais econômicos, ou mais ecológicos, etc. O próprio intuito de projetar já é uma escolha entre intervir ou não sobre o território, e este é um preceito de ordem social e política, onde a técnica apenas corroba ou não uma hipótese.

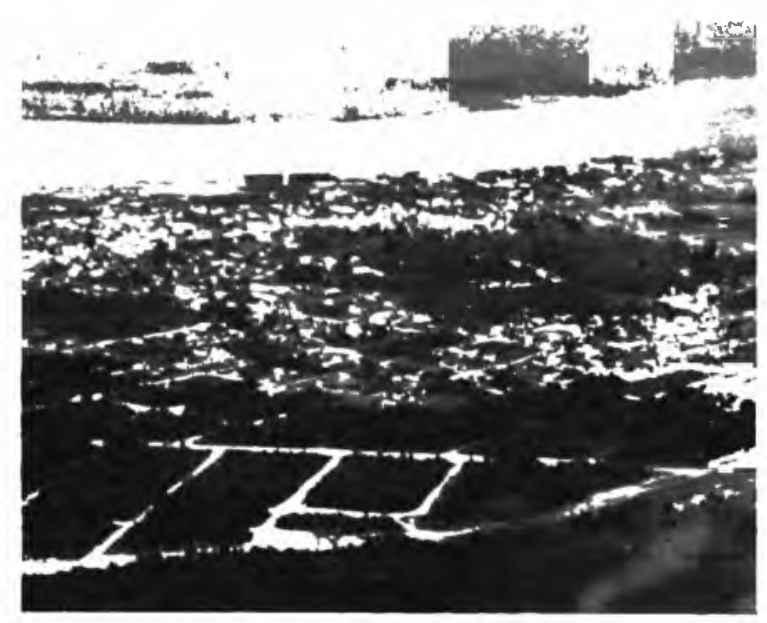

Foto 3 - Loteamentos na Ilha Comprida (Litoral sul de São Paulo) ocupando áreas lindeiras à praia, antes recobertas por matas de restinga (Foto: Silvio S. Macedo) 


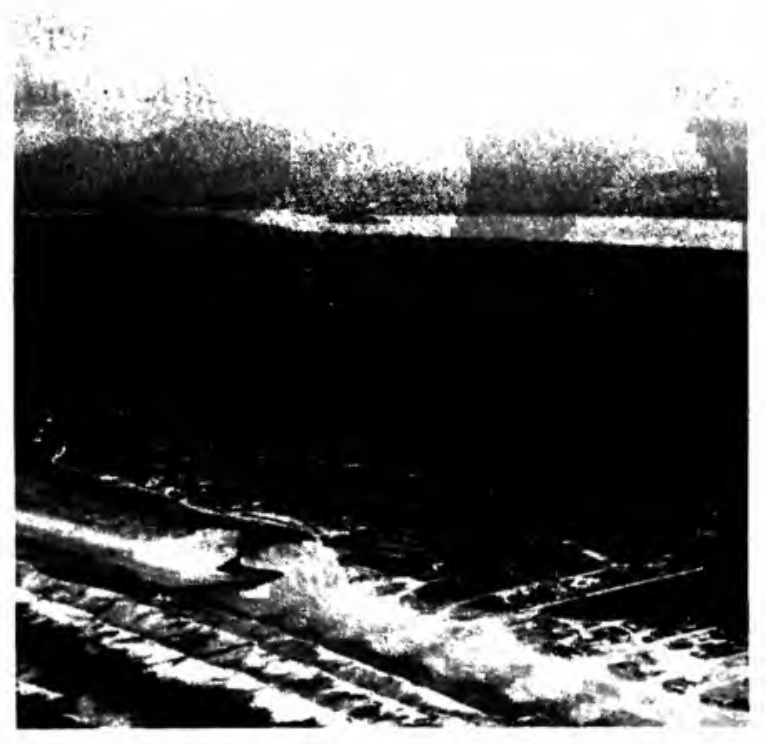

Foto 4 - As vizinhanças urbanas podem e comprometem a qualidade da água e a integridade dos diversos ecossistemas, como no caso a cidade de Cananéia

(Foto: Silvio S. Macedo)

\section{CONCLUSŌES}

O que observamos na realidade cotidiana é o oposto do pretendido pelas políticas vigentes de uso do solo e exploração de recursos naturais: as áreas de preservação são ameaçadas por ocupações clandestinas, pela exploração ilegal. pela poluição conseqüente do despejo de esgotos e deposição de lixo doméstico daqueles mesmos turistas que "zelam" pelas áreas verdes (dos seus jardins, talvez). A educação ambiental e a ocupação planejada são estratégias de preservação e não de destruição ou degradação da natureza. Devem ser vistos como instrumentos de desenvolvimento. Só o envolvimento da sociedade com a questão ambiental pode provocar uma mudança na exploração de recursos, no próprio modus vivendi. É uma atitude política, principalmente, é uma opção para uma mudança de valores que propiciem um futuro viável, ou seja, um futuro que ofereça, pelo menos, as mesmas condições de vida que temos atualmente. ou que tínhamos há algumas décadas, quando a situação dos ecossistemas terrestres não era tão comprometida quanto hoje.

O problema da conservação de recursos naturais é global, exigindo uma postura e visão mais amplas, mais cosmopolitas, objetivas e realistas, com propostas pertinentes à emergência da situação ambiental atual. Oferecer uma melhor qualidade de vida nas cidades é essencial para garantir a sobrevivência.

$\mathrm{O}$ arquiteto deve responder às necessidades da sociedade de organização sobre 0 suporte ecológico, com propostas não prontas e acabadas, mas que orientem discussões, admitem possibilidades e alternativas e ofereçam opções de ações de planejamento conjuntas com a sociedade, que de maneira recíproca dará respos- 
tas ao desenho proposto, intervindo e assimilando ou não os projetos de intervenção. O planejador saberá ouvir estas respostas, se admite a sociedade como agente transformador da paisagem.

\section{BIBLIOGRAFIA}

AUP-836 Meio ambiente humano e planejamento da paisagem notas de aula. São Paulo: FAUUSP, 1992.

CENIQUEL, Mário. Paisagem e Habitat. In: Paisagem e Ambiente - Ensaios IV. São Paulo: FAUUSP, 1992.

CULLEN, Gordon. Paisagem urbana. Lisboa: Edições 70, 1983.

KRAF-Planejamento Ambiental S/C. Estudo de Impacto Ambiental da Barra do Itaguaré. São Paulo, 1990.

MACEDO, Silvio S.; PELLEGRINO, Paulo R. M. Ética e estética: o desenho do litoral. In: Paisagem e Ambiente - Ensaios III. São Paulo: FAUUSP, 1989.

MCHARG, Ian. Design with nature. London: Oxford Press, 1969.

MEINING, D. W. The beholding eye: ten versions of the same scene. Louisville, Landscape Architecture, jan. 1976.

PELlEGRINO. Paulo R. M. Paisagem e ambiente: um processo de aproximaçāo no setor oeste da macrometrópole de Sāo Paulo. São Paulo, 1987. Dissertação (Mestrado) FAUUSP. 